\title{
Review Article \\ Hybrid Carbon-Carbon Ablative Composites for Thermal Protection in Aerospace
}

\author{
P. Sanoj and Balasubramanian Kandasubramanian \\ Department of Materials Engineering, Defence Institute of Advanced Technology (DIAT) (DU), Girinagar, Pune, \\ Maharashtra 411025, India \\ Correspondence should be addressed to Balasubramanian Kandasubramanian; meetkbs@gmail.com
}

Received 7 October 2013; Revised 19 January 2014; Accepted 19 January 2014; Published 6 March 2014

Academic Editor: Hui Shen Shen

Copyright (C) 2014 P. Sanoj and B. Kandasubramanian. This is an open access article distributed under the Creative Commons Attribution License, which permits unrestricted use, distribution, and reproduction in any medium, provided the original work is properly cited.

\begin{abstract}
Composite materials have been steadily substituting metals and alloys due to their better thermomechanical properties. The successful application of composite materials for high temperature zones in aerospace applications has resulted in extensive exploration of cost effective ablative materials. High temperature heat shielding to body, be it external or internal, has become essential in the space vehicles. The heat shielding primarily protects the substrate material from external kinetic heating and the internal insulation protects the subsystems and helps to keep coefficient of thermal expansion low. The external temperature due to kinetic heating may increase to about maximum of $500^{\circ} \mathrm{C}$ for hypersonic reentry space vehicles while the combustion chamber temperatures in case of rocket and missile engines range between $2000^{\circ} \mathrm{C}$ and $3000^{\circ} \mathrm{C}$. Composite materials of which carbon-carbon composites or the carbon allotropes are the most preferred material for heat shielding applications due to their exceptional chemical and thermal resistance.
\end{abstract}

\section{Introduction}

Discovery of carbon-carbon composites in 1958 by Brennan Chance Vought Aircraft created an opportunity to these principle materials for heat shielding appliances due to their high strength and thermal resistance [1]. Rayon carbon fabric reinforced phenolic $(\mathrm{C}-\mathrm{Ph})$ composites are the broadly used thermal protection systems due to the low thermal conductivity of the rayon fabric and high char yields of the phenolic resin. In general, carbon phenolic composites show better ablation resistance and continued enhancement of ablative property with the development of a thinner ablative composite structure for better pay load and fuel efficiency [2]. The Space Shuttle Columbia disaster occurred on February 1, 2003, due to the inadequate impact resistance of the thermal insulation foam in the external tank against air, as the spacecraft reentered the earth's planetary atmospheric domain. The displaced reinforcement foam damaged Columbia’s left reinforced carbon-carbon (RCC) panels thereby causing the unfortunate accident. This incident paves way for a detailed research to enhance impact tolerances, thermal resistance, and fracture toughness of the RCC panels [3]. Polymer nanocomposites are the three phase composite systems invented by Toyota research group, wherein nanosize particles, dispersed in the two phase fiber reinforced composites, exhibit enhanced structural rigidity and ablation resistance [1]. Nanocomposites have the capability to withstand the simultaneous action of thermal stresses and mechanical impact loads. Addition of various nanoparticles such as nanosilica, montmorillonite (MMT), nanoclays, and polyhedral oligomeric silsesquioxane (POSS) with surface functionalization acts as thermal insulative elements for improving char layer integrity and toughness. Three phase composite system with heterogeneous composition (fiber reinforcement, matrix, and nanofillers) exhibits complexity in its ablation behaviour [4]. The scientific insights into the ablation and decomposition behaviour of the composite materials lead us to a trustworthy analysis of the composite performance at high temperature working environment. This review has focused on the recent developments in the carbon-carbon composites and resultant thermal protection mechanisms. Microstructural changes during the transition 


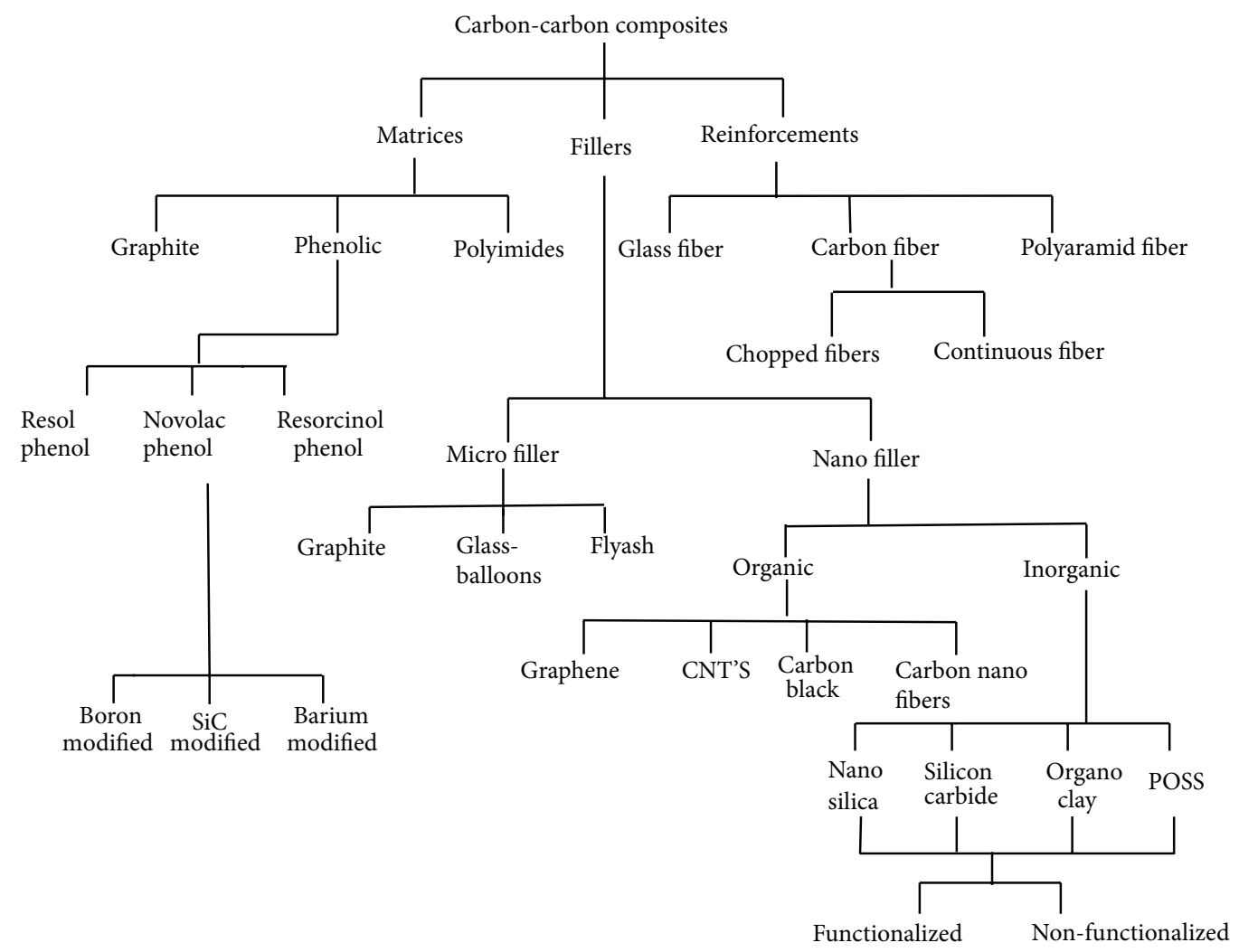

FIGURE 1: Carbon-carbon composite system and its constituent elements [8].

from two phase composite system to three phases have been discussed in detailed manner.

\section{Structure Description of Hot Zone Assembly}

Missile structures are the extremely crucial components in aerospace industry. They should have high structural integrity and fire resistance against severe lateral pressure and thermal cyclic loading. Nozzle, the exhaust duct of the solid rocket motor, gives thrust for the missile projectile motion [5]. During missile flight, nozzle experiences an impact of jet flow with high temperature and pressure. Since even slight degradation in nozzle structure severely affects the engine performance, structural integrity is the main concern during nozzle operational period. The nozzle liner is the lining system in the nozzle inner counter to form insulation barrier. The high temperature fluid flow in the inner contour of the nozzle system creates a soaring thermomechanical stresses through the liner cross section. This degrades the nozzle throat and widens the throat area of cross section [6]. This phenomenon causes a reduction in thrust and nozzle operational efficiency. Erosion rate of the composite system depends on the thermal insulation capacity of the ablative composite char layer. Minimum surface recession rate of the char layer shows an efficient thermal shielding capacity of the ablator. Windhorst and Blount have revealed the usage of pyrolytic graphite as thermal insulation and its brittle failure due to the thermomechanical stresses [7]. It is reported that phenolic impregnated carbon composite is a popular ablative material for rocket nozzle liners due to its shielding against combustion flame and high velocity erosive fluid flow [8]. These extreme working environments demand high structural integrity for nozzle liner with minimum structural degradation.

\section{Ablative Materials}

Figure 1 shows the constituent elements in the carbon-carbon composites.

3.1. Carbon Fibres. Carbon fiber is a synthetic fiber reinforcement with a diameter of about $5-10 \mu \mathrm{m}$. The crystalline arrangement of the carbon atoms parallel to the fiber axis enables high strength-to-volume ratio of the fiber with excellent applications for structural components [9]. The precursors used for the large-scale production of carbon fibers are PAN, Rayon, and petroleum pitch through melt or solution spinning. PAN-based fibres show better mechanical strength as compared to the other fibers [10]. The carbon felt has been fabricated by alternatively stacked weftless piles and shortcut-fiber webs by needle-punching technique. This technique minimizes the fiber bend and breakage with the capability to tailor the properties by weaving in appropriate directions. Normally nonwoven carbon composite shows highest tensile strength over woven materials [11]. Weave pattern orientation of the carbon fabric affects the heat diffusion rate through 


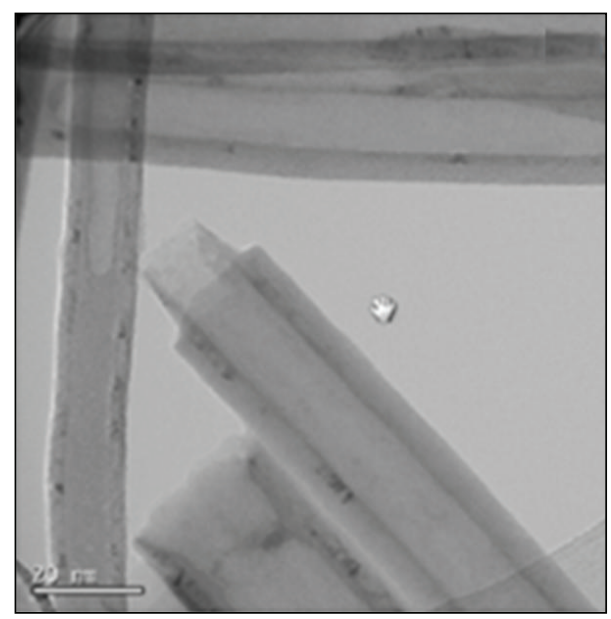

(a)

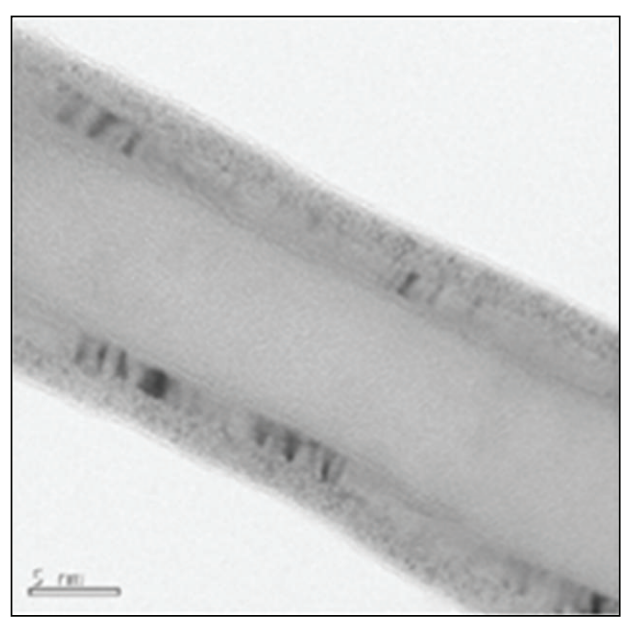

(b)

Figure 2: TEM image of Vapour Grown Carbon Fibers (a) magnification $20 \mathrm{~nm}$, (b) magnification $5 \mathrm{~nm}$ [21].

the cross section of the composite. Kuo and Keswani studied the changes in the weave pattern of carbon fibers in different directions and altered specific properties of carbon composite [5]. Surface-treatment of the carbon fibres is a current advancement in the fiber technology, in which surface treatment by means of physical or chemical method improves the adhesion between carbon fiber and polymer matrix [12]. Production of carbon fiber through fiber spinning is highly expensive process. The usage of mesophase pitches shows efficient fiber reinforcement with improved cost effectiveness. Chand has described the mesophase pitches, which are of liquid crystalline nature. During graphitization step, mesophase pitches form a graphitic crystalline structure with high modulus carbon fibers with high stiffness [11]. Strength improvement in the fibre reinforcement is mandatory for ablative composites due to dependency of the ablation rate of composite with the fiber reinforcement morphology. More research needs to be focused over the enhancement in fiber morphology, design of fiber laminate orientation, and cost effectiveness in fiber production.

3.1.1. Vapour Grown Carbon Nanofiber. Vapour grown carbon fibers (VGCFs) are the recent desirable materials in thermal shielding composites due to their superior thermal insulation, low thermal conductivity $(0.45-0.58 \mathrm{~W} / \mathrm{mk})$, and high thermal shock resistance [13]. These nanofibers (VGCNFs) are cylindrical nanostructures with graphene layers arranged in a stacked cones shape. Synthesis of the VGCNFs is carried out through decomposing gas-phase molecules at high temperature (deposition of carbon in the presence of a transition metal catalyst on a substrate) [14]. Tibbetts et al. grew a series of different diameter $(7-30 \mu \mathrm{m})$ vapour grown carbon fibers and from these carbon fibers it was observed that young's modulus and tensile strength decreased with increase in diameter of fibers [15]. Dispersion and homogeneity are the specialty of VGCNF in the composite system. It leads to uniformity of properties throughout the volume of composite. Figures 2(a) and 2(b) illustrate the fiber morphology of the vapour grown carbon fibers in different magnification. Patton et al. confirmed that $65 \%$ vapour grown carbon fiber loading in VGCF composite get a good thermochemical ablation resistance for space shuttle reusable solid rocket motor [13]. Recent research on the effect of different oxidative surface treatments (nitric acid, plasma, air, and carbon dioxide) on the fibres surface shows the effectiveness of the nitric acid and plasma treatments for improving the surface reactivity without altering the morphology of the fibres. This enhances the adhesion of VGCNFs to the phenolic matrix system [16]. Fiber orientation in Vapour Grown Carbon fiber is a critical factor during the modelling of the composite system $[17,18]$. This can be statistically modelled by an orientation distribution function describing the probability of finding fibres with any given orientation [19]. Advani and Tucker introduced a compact tensor description for fibre orientation, which allows easy integration with conventional rheological and mechanical tensor descriptions. Due to these advantages, it is now widely used in works on short fibre composites [20].

\subsection{Carbonaceous Matrix}

3.2.1. Phenolic Resin. Matrix materials in the carbon-carbon composite have significant functional properties as it holds the reinforcement fiber and impart structural integrity to the composite system. Resol type Phenolic systems have attracted great scientific interest as they can be effectively used as a matrix system in ablation resistant composites [21]. During the fire exposure, phenolic resin receives heat in the initial stage and decomposes to char and forms a thermal insulation layer. Large number of aromatic rings in the Resol type phenolic resin results high carbon yield and effective char formation ability [27]. High char retention of the Resol type phenolic resins makes them an effective applicant for ablative nozzle liner application. Presence of hydroxyl and methyl linkages in the phenolic is prone to oxidation and demands further modification in the phenolic resin compound for 


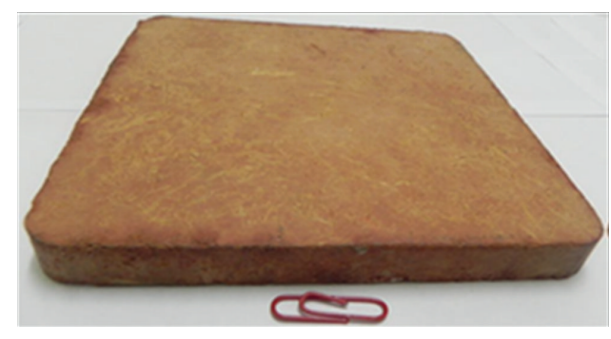

(a)

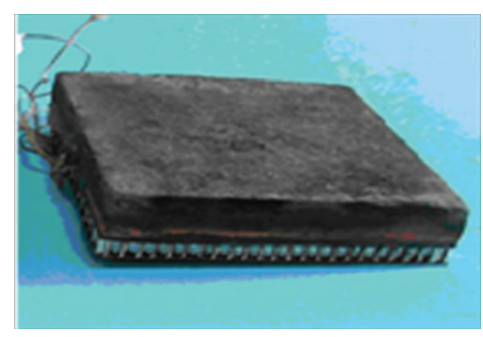

(b)

FIGURE 3: (a) 15-mm thick silica fibre-reinforced phenolic syntactic foam. (b) Photograph of phenolic foam after aerothermal test [22].

practical usage as thermal ablators [28]. Chemical modifications have been well investigated to improve oxidation resistance of phenolic resin. Modification of phenolic resin with elements such as Boron, Titanium, Molybdenum, and Phosphorous shows better ablation resistance and char yield [29]. Improvement in the tribological properties of the phenolic resin enhances the wear and aerodynamic shear resistance of the phenol based carbon composites [30]. Yi and Yan studied the mechanical and tribological properties of phenolic composite dispersed with several inorganic fillers like calcined petroleum coke (CPC), talcum powder (TP), and hexagonal boron nitride (h-BN) [31]. The phenol based composite with $10 \% \mathrm{~h}-\mathrm{BN}$ shows excellent friction stability and wear resistance at various testing conditions beyond $125^{\circ} \mathrm{C}$ and results in formation of compact friction film on the rubbing surface of composite. There is always a constant effort for improving the processability, toughness, and char yield of the phenolic resin by compounding with highly stable additives such as $\mathrm{SiC}$, Boron nitride, Nanosilica, and zirconium diboride [32]. This modification led to better clasping of the turbostratic carbon, formed as a result of high temperature pyrolysis of hydrocarbons, consequently reducing the erosive loss of the char layer [33]. In recent years, Polyhedral Oligomeric Silsesquioxane finds attention due to their nanosize in organic cage like cluster morphology which produce best charred surface on burnt samples with an enhanced ablation performance in carbon-carbon composite [34].

3.2.2. Phenolic Based Carbon Foam. Phenolic foams are the light weight ablators with an exceptional fire resistance used in thermal insulation system for aerospace application. Cost effectiveness and absence of dripping molten plastic at the stage of combustion are the added advantages of phenolic based carbon foams. Generally, pure phenolic resins foam does not have the required strength to withstand the aerodynamic stresses and thermal fluctuations due to its friability [35]. Phenolic foam reinforced with synthetic fibers is the recent potential material for thermal insulator applications to improve composite strength, toughness, and effective fire resistance. Zhou et al. developed lightweight glass fiber reinforced phenolic foam with high mechanical performance and excellent flame resistance and noticed the improvement in storage modulus of the foam with reduction in loss modulus [36]. The current research is primarily focusing on the improvement in toughness and peel strength of the carbon phenolic foams through reinforcement of flexible synthetic fibers like Glass and Kevlar. Short chopped glass fibers treated with coupling agents reportedly increased the strength, toughness, and dimensional stability of phenolic foams. However, Shen et al. studied the improvements in peel strength of carbon phenolic foams with Kevlar fiber reinforcement and obtained multiple-fold enhancement in fracture toughness [37]. Various research groups have attempted to modify the phenolic foam through nano- and microsize filler dispersion like carbon black, talc, nanosilica, fly ash, asbestos, and cork flours. Exfoliated phenolic resin/montmorillonite nanocomposite shows excellent thermal insulation behaviour as Montmorillonite (MMT) layers wrap around the bubbles of the composite foams during high temperature environment. John et al. developed mediumdensity foam composites based on silica fibre-filled phenolic resin which shows maximum tensile strength at silica fibre concentration of $15 \%$ by volume with K37 glass balloons [22]. The reinforcement of silica fibre phenolic foam with microglass balloons before and after the aerothermal test (the black colour on the surface of the sample is an emissivity coating) is illustrated in Figures 3(a) and 3(b), respectively. Nucleating agents are the effective materials used to reduce bubble size with enhancement of strength and toughness of phenolic foam. Hollow carbon microspheres from hollow phenolic microspheres have good potential to be attractive functional fillers for carbon foams [38]. It shows a significant improvement in the fracture toughness of syntactic foam at 20-30 vol.\% microspheres [39]. Activated carbon reinforced microcellular phenolic foams are the incipient in heat shielding application as they can be effectively used for thermal shielding due to the low thermal conductivity, density, and reliable compressive strength [40].

3.3. Elastomeric Matrix. Elastomeric based heat shielding materials is a novel concept in the ablative composites due to their excellent ablation resistance, char yield, and high strain rate [41]. The high strain rate performance with excellent dimensional flexibility significantly reduces the induced thermal stresses during thermal expansion of composites. The elastomers show high resistance against rapid removal of char by mechanical shear and spallation during aeroheating loads [42]. Silicone and Nitrile rubber based ablative materials are the initial developments in the elastomeric matrix system due to their high strain rate 


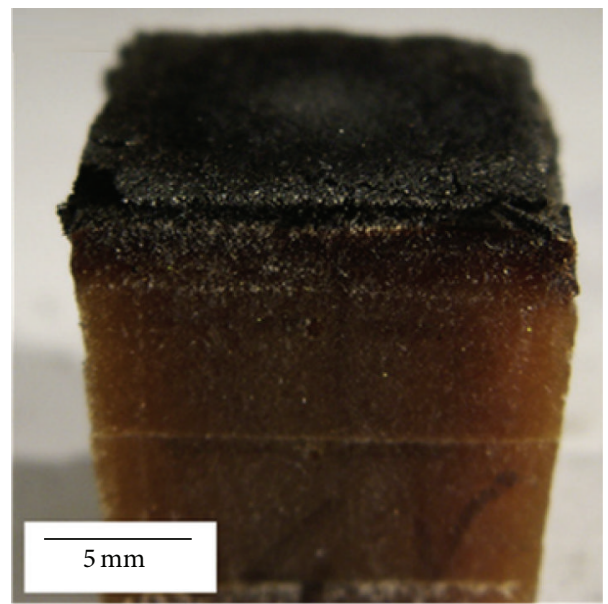

(a)

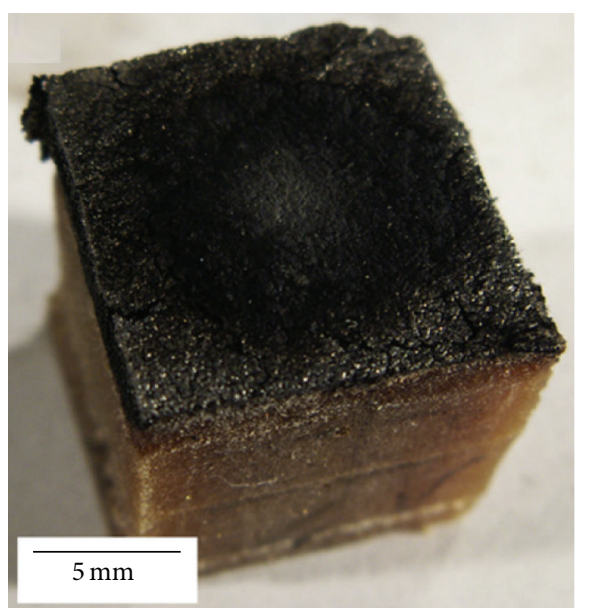

(b)

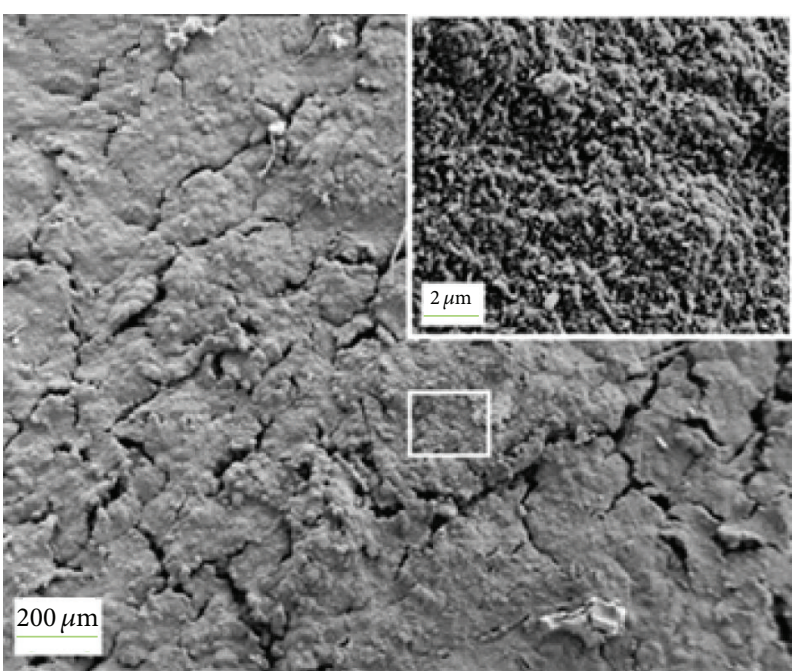

(c)

FIGURE 4: ((a) and (b)) Postburning images of the EPDM based Kynol tested materials. (c) SEM image of the burnt surface of EPDM/Kynol samples [23].

with reduced thermal stresses. Silicone based elastomeric ablators show better thermal insulation characteristics due to the formation of siliceous char, which is an inert char layer having excellent thermal stability. Among the other polymeric insulators, elastomeric ablators show high density, limited shelf life, and inferior thermal resistance, which limit their wide applications as thermal insulators. Ethylene propylene diene monomer (EPDM) rubber based matrix system is a novel approach in the elastomeric heat shielding materials due to its high oxidation resistance with excellent low temperature properties [43]. EPDM matrix system can be effectively strengthened through reinforcement of glass, carbon, Kevlar, and polysulfonamide fibers. The low density and high thermal capacity with excellent fire resistant of these synthetic fibers effectively improve the thermochemical properties of elastomeric ablative composites [44]. Flame retardant additives such as ammonium polyphosphate are used as an efficient method to enhance thermal insulation properties of the shielding composites.
Recently, Jia et al. have studied the reinforcement effects of polysulfonamide fibers in the EPDM matrix as a thermal insulation fibers and also noticed the enhancement in thermal stability due to the presence of additional sulfone group $\left(-\mathrm{SO}_{2}-\right)$ in the main chain of the sulfonamide fibers [45]. Similarly, Natali et al. have studied the reinforcement effects of Kynol fibers, made by acid-catalyzed cross-linking of meltspun Novolac and noticed that Kynol fiber shows excellent thermal properties as compared to Kevlar fibers. Figures 4(a) and 4(b) represent the postburning images of the EPDM based Kynol tested materials and Figure 4(c) illustrates the SEM image of the burnt surface of EPDM/Kynol samples [23]. Since the thermal insulation is inversely proportional to the density of the materials, low density elastomeric ablators need to be designed for a better ablation performance. Reinforcement of additives with a density gradient is an effective approach for the development of a light weight ablator without compromising on the ablation performance. In the recent period, hybrid ablative composites are a topical 
concept in which two or more fibers reinforced in the matrix system for optimized balance properties in the thermal insulation system. Regarding this, Ahmed and Hoa have studied the effect of a chopped carbon fiber (CCF) and aramid fiber on pulp as hybrid reinforcement for ethylene propylene diene monomer (EPDM) along with ammonium polyphosphate (AP) flame retardant agent and noticed improvement in the ablation performance with an improved thermomechanical performance [46].

\section{Nano Filler Enabled Hybrid Composite}

Nanoparticles (or nanopowder or nanocluster or nanocrystal) are the microscopic particles which are having exceptional high surface area to volume ratio that makes them an effective filler reinforcement for ablative composites. Reinforcing effects of the nanoparticle mainly depend on the crystalline microstructure and effective interfacial bonding with the parent matrix [47]. Nanofiller embedded ablative composites show enhancement in thermal degradation and ability to resist high-temperature erosive aerodynamic shear forces. This is mainly due to its high thermal stability, low thermal conductivity, and high adhesive bonding with the parent matrix. Adhesive bonding is mainly related to the improvement in interlaminar shear strength (ILSS) in hybrid composite structure [24]. Recent research works cover the development of carbon nanofibers, nanoclay, and CNT in phenolic resin for better ablation resistance. Dash et al. studied the mechanical characterization of a Red Mud filled hybridized composite and noticed improvement in flexural and tensile properties [48]. Generally, the dispersion of the nanoparticle in the fiber reinforced composite system is in the range of $1-4 \mathrm{wt} \%$ [49]. Beyond the percolation threshold, mechanical and ablation resistance of the composite decreased due to the agglomeration of the nanofillers. Uniform dispersion of nanofillers effectively improves the structural integrity of the char layer during ablation. Inorganic fillers are found as more suitable materials for thermal insulations due to the presence of thermal barrier properties and surface morphology [50].

4.1. Organic Fillers. Higher aspect ratio and inherent thermomechanical properties are the key factors of organic fillers for their effective usage as reinforcing agent to protect the carbon fibers and matrix from aerodynamic forces. Organic fillers include single wall carbon nanotube (SWCNT), multiwall carbon nanotube (MWCNT), carbon nanofiber, carbon black, and graphene. During ablation, MWCNT in the char layer reemits the incident heat radiation in to gas phase. This reemission decreases the heat transfer rate into the inner layers of the composite panels and reduces the endothermic pyrolysis [51]. So the presence of MWCNT leads to an improvement in the thermal insulation and reduction in mass loss. Tirumali et al. studied different morphological nanofibers (stacked-coin-type) and their morphological shape variation with respect to various mechanical and chemical treatments [47]. Vapour-grown carbon nanofibers have the potential to enhance the structural properties of the char due to its high aspect ratios and fine diameter ranging from $15 \mathrm{~nm}$ to $100 \mathrm{~nm}$ [46]. In a review by Tirumali et al. on Epoxy composites of Graphene Oxide (GO), the morphological characteristics of Graphene Oxide and Graphene were studied and illustrated that platey like morphology of GO/Graphene enhanced their reinforcement effect on the polymeric system [47]. Figure 5 shows the charred surface of the MWCNT dispersed in carbon-carbon composite. $2 \mathrm{wt} \%$ of filler addition makes a thermal barrier protection layer over the carbon fiber and avoids its peel off from the bottom layer.

4.2. Inorganic Fillers. The inorganic nanofillers are the prominent filler reinforcement in the composite material for heat shielding applications. These nanofillers, such as montmorillonite (MMT) nanoclay, fly ash, nanosilica, zirconia diboride, calcium carbonate, and barium sulphate, are being used for their reinforcing ability to enhance the tribological and thermal properties of the polymer matrix. Microsized fillers require large amount of filler loading for a uniform char layer over the surface [47]. Nonuniform dispersion and large void region in microsize fillers create a local nonuniform erosion rate with a rough surface and hence are prone to erosion. Nanofillers show a significant reinforcing effect compared to microsized fillers due to their higher specific surface area and volume effects. The in-organic fillers melt during high temperature exposure and form a viscous melt layer over the burned surface. This layer acts as a protective antioxidation barrier and radiative cooling system in the high temperature burned surface. Molten fused silica reacts with char and produces a SiC phase. Silica melt layer absorbs significant amount of heat by an endothermic process during its phase transformation and enhances the cooling rate [52]. Srikanth et al. studied the effect of nanosilica in carbon phenolic composites and identified an improvement in the ablation resistance along with reduced thermal conductivity and improved interlaminar shear strength [52]. Xiao et al. have reported that addition of zirconium diboride to carbon phenolic composite significantly improves the ablation resistance during the fire exposure [53]. Polyhedral oligomeric silsesquioxane is reported to be efficient filler for reducing thermal conductivity and ablation resistance in the carbon phenolic composites [53]. Figure 6(a) shows the eroded carbon fibers during plasma arc treatment, while Figure 6(b) shows the protective layer of the melt nanosilica over the carbon fibers.

4.3. Inorganic Nanocoating on Carbon Fibers. Surface coating on the reinforcement fiber is the new development in fiber reinforced composite system. The aim of coating on the reinforced fibers is to improve the oxidation resistance and adhesive bonding of the carbon fiber with surrounding matrix. Optimum coating thickness is significant constraint in order to obtain a good compressibility of the hybrid composite system, which maintains the fiber reinforcement volume $\left(\% V_{\text {fiber }}\right)$ in the composite system. Srikanth et al. studied the effect of zirconium oxide coating (thickness 700$900 \mathrm{~nm}$ ) on the carbon fabric and found the reduction in thermal conductivity and the rear face temperature. Surface 


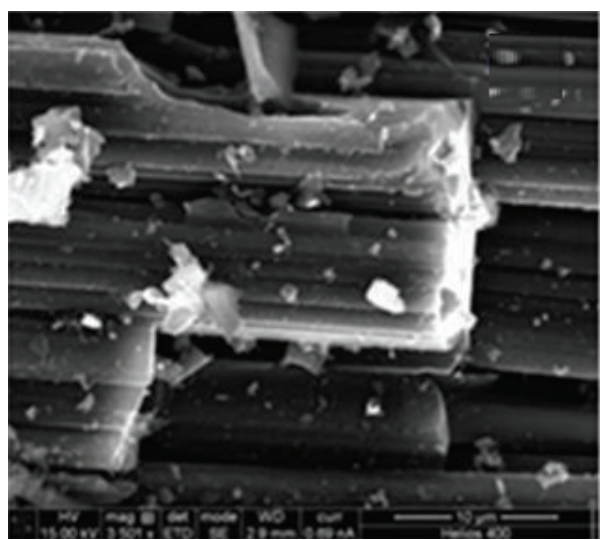

(a)

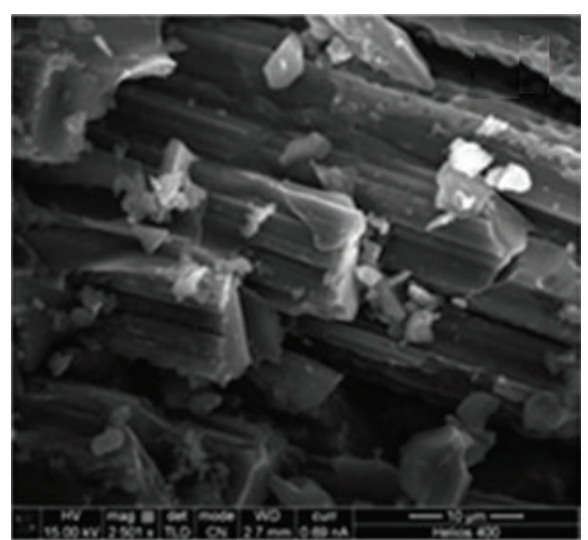

(b)

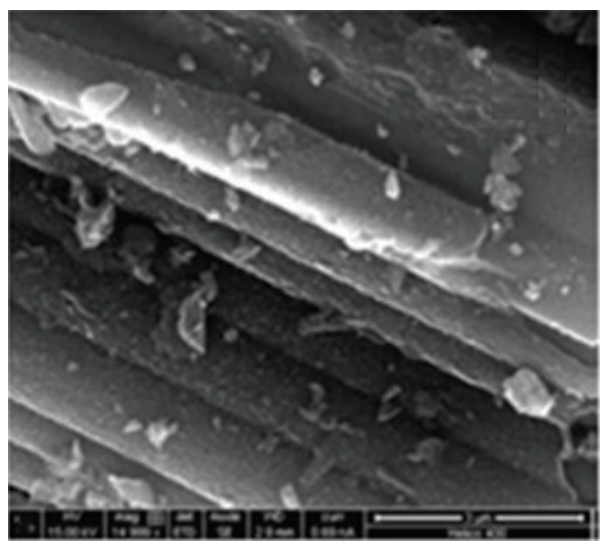

(c)

Figure 5: SEM images of (a) $0.5 \mathrm{wt} \%$, (b) $1 \mathrm{wt} \%$, and (c) $2 \mathrm{wt} \%$ MWCNTs ablative nanocomposite samples [18].

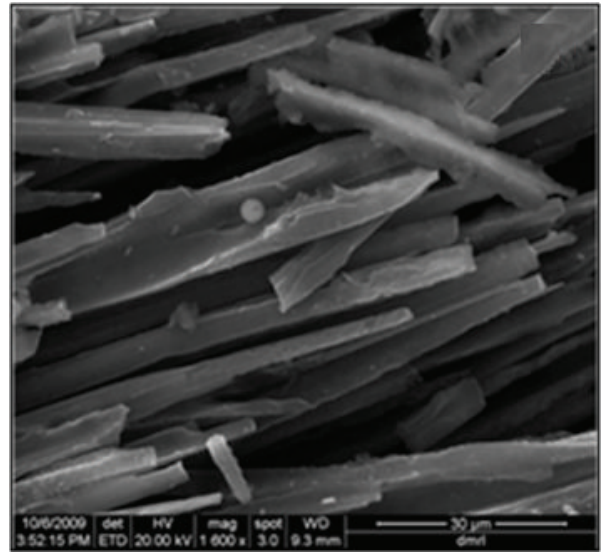

(a)

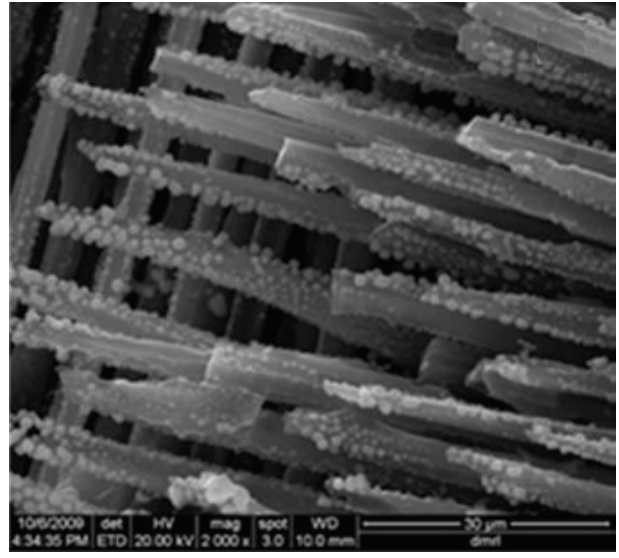

(b)

Figure 6: (a) Ablated surface of blank C-Ph composite, (b) 2.0 wt.\% nanosilica C-Ph after ablation [24].

coating causes the reduction in the effective interfacial area between the fiber and the matrix which leads to a decrement in flexural modulus and interlaminar shear strength [54]. Thermally sprayed tungsten carbide and silicon coating are an effective method for effective thermal barrier shielding [55]. Recently, Ryu has fabricated $\mathrm{C} / \mathrm{SiC}$ functionally graded coating for reducing the thermal residual stresses between carbon composites and $\mathrm{SiC}$ coating layer. As per his observation $\mathrm{SiC}$ rich compositional layer in the Functionally Graded material (FGM) shows effective release of the thermal stress and increment in oxidation resistance [56]. 


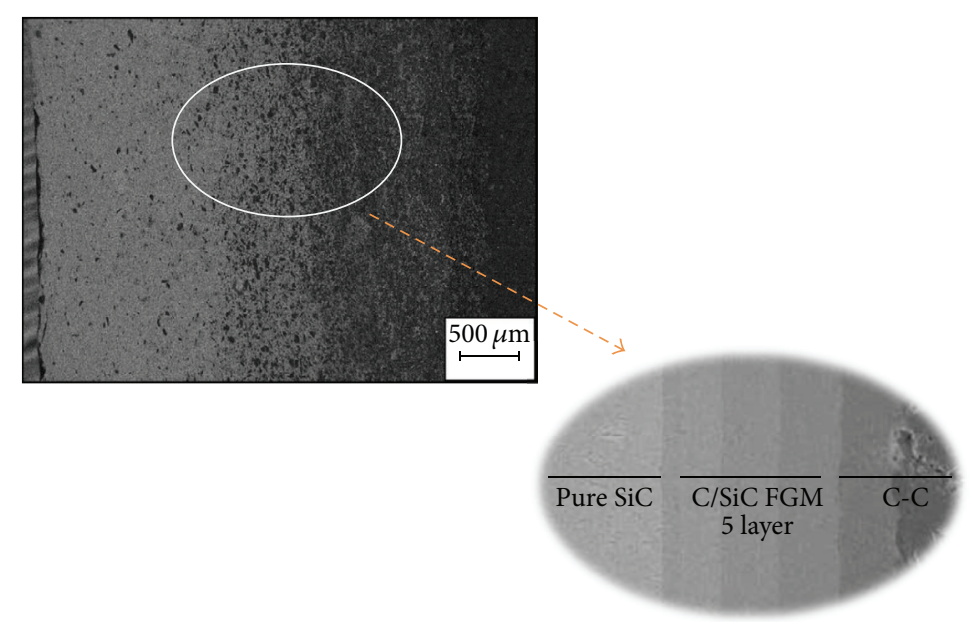

FIGURE 7: SEM image of the linear continuous gradient microstructure of carbon-based SiC/C FGM and their magnified intermediate transition layers [25].

\section{Functionally Graded Composites}

Functionally graded composite material (FGM) is composed of two different phases in which volume fraction changes gradually along at least one dimension of the solid. Functionally graded nanocomposite features layer by layer variation in the filler composition and their concentration density profiles in order to realize a designed functionality. Effective design of the various layers in FGM makes minimum heat diffusion through thickness with maximum thermal insulation [57]. Functionally graded materials are considered to have smooth spatial variation of microstructure and homogenized material properties [26]. This structural variation improves the compressive strength and there is enhancement in the fracture and fatigue strength. Spatial variation of microstructure significantly minimizes the thermal delamination which takes place through the difference in the thermal expansion coefficient of the two materials [58]. The distribution of residual thermal stresses is very important in the soundness of FGM composite. Figure 7 shows the SEM image of the linearly continuous gradient microstructure of carbon-based $\mathrm{SiC} / \mathrm{C} \mathrm{FGM}$. It signifies that smooth gradient interface in the FGM ensures narrow transition from one material to another and decreases the thermal residual stresses. Srikanth et al. developed a composite panel in which the top layer consists of carbon nanotube (CNT) hybrid carbon phenolic composite and in the bottom layer Zirconium Oxide hybrid $\mathrm{C}-\mathrm{Ph}$ composite. Presence of the CNT in the composite enhances the flexural and shear strength of the composite, but during charring composite loses its structural integrity due to the improvement in thermal conductivity of the CNT [50]. Powder metallurgical approach including plasma spraying method has been widely used in the fabrication of thermal stress relief type of functionally graded materials [59]. Liu et al. reported the modelling study of thermal stress in SiC/C functionally graded composite by finite element numerical models and noticed the decrement in thermal stresses with increasing the layer number. The optimum intermediate graded layer and pure $\mathrm{SiC}$ layer thickness was 3-4 mm and
0.5-1 mm [60]. Bafekrpour et al. studied the flexural properties of the carbon nanofiber/phenolic functionally graded composite by varying the compositional gradient of carbon nanofiber and noticed the improvement in flexural properties of FGM [61].

\section{Ablative Mechanisms}

The ablation mechanism of the carbon-carbon composite in nozzle inserts is a heterogeneous chemical interaction between the propellant combustion products and nozzle materials [62]. It is a thermal protection mechanism in which high temperature radiant energy from the combustion chamber acts on the material surface and dissipated through a series of endothermic reaction processes (thermochemical, thermophysical, and thermomechanical). When the throat surface temperature is less than of 2000-2500 K, ablation mechanism is dominated by chemical kinetics. The temperature at $2000-2500 \mathrm{~K}$, the reaction is significantly controlled by diffusion rate [62]. The graphite or carbon-carbon materials validate a superior advantage since their sublimation at $1 \mathrm{~atm}$ was about $4000 \mathrm{~K}$ and it increased with the increase in pressure. Ablation concedes through a combined action of heat transfer, chemical reactions, and fluid flow and finally the material is consumed [63]. Figure 8 shows the ablation mechanism in the carbon based polymer matrix ablatives and illustrates the combined thermomechanical decomposition phenomena during ablation process. During the space craft propulsion, hypersonic flow of hot air creates an external boundary layer of low pressure over the ablation surface. The circulation of the dissipated heat occurs within this boundary and passes the heat away from the material surface. This phenomenon led to an added advantage for an efficient thermal shielding mechanism [50]. Normally, the thermochemical degradation of outer layer of the carbon-carbon composite takes place through convectional heat transfer in which pyrolyzing layer diffuses towards the heated area of the shield. In the nozzle design, the pressure and temperature 


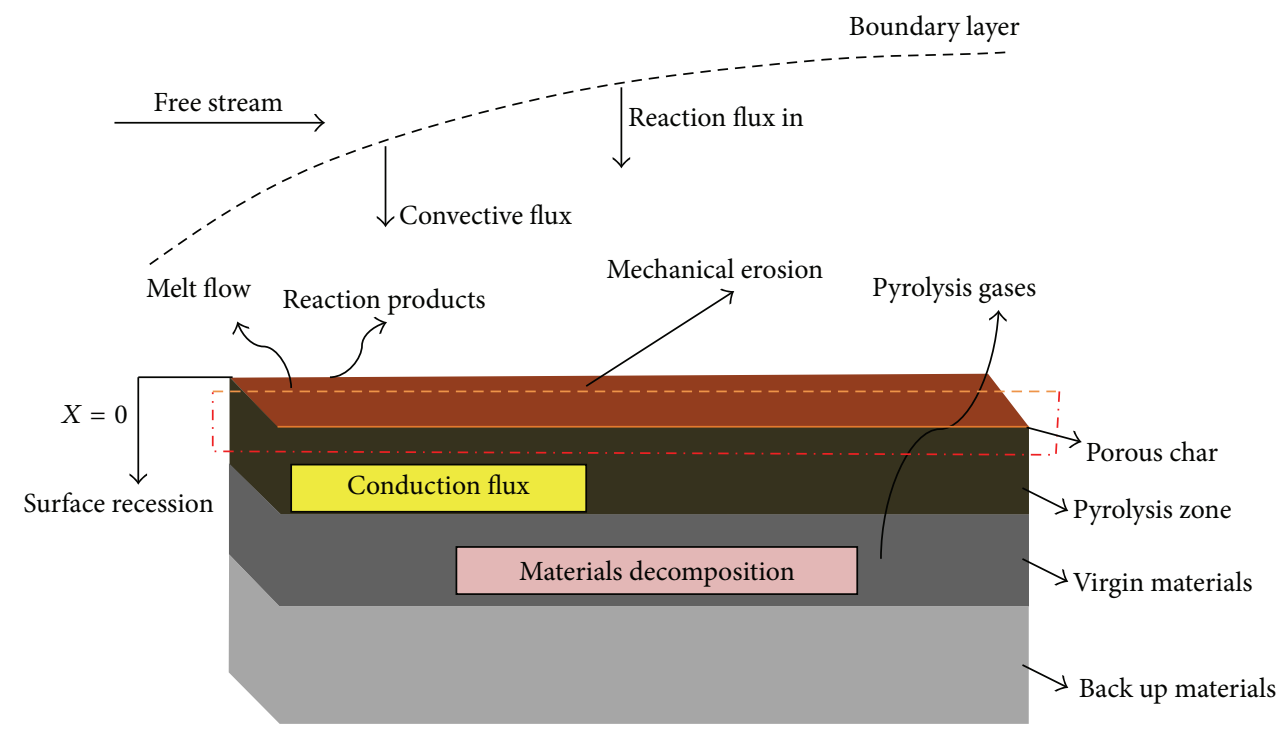

FIgURE 8: Pyrolysis mechanism carbon based polymer matrix [26].

of the combustion gases at the throat could not match the condition for sublimation, so sublimation was neglected as an ablation mechanism for the throat erosion [51]. Interface region of the fiber/matrix and the defective regions of the composite are more prone to ablation. This is due to the lower activation energy and high reactivity of the defective region in the composite system $[64,65]$. The ablation always developed along the direction of interface-to-fiber and interface-tomatrix due to the high oxidization tendency of the interface region. Donghwan has explained ablation mechanism by an erosive phenomenon, who reported that decomposition of the ablative materials takes place through thermal oxidation during fire exposure at high temperature of $2000-3000^{\circ} \mathrm{C}$, resulting in the formation of char and peels off from parent layer by the combustion flame [12]. These typical ablation characteristics suggest that super lightweight carbon ablators require high thermal degradation temperature and less dense microstructure to perform as an efficient heat shielding material [66]. Figure 9 shows the schematic of parameters influencing ablation resistance of the carbon/carbon composite.

6.1. Thermal Decomposition. In case of carbon-carbon polymer composites, decomposition takes place through the viscous softening, melting, decomposition, and volatilization [67]. So a meticulous study over the decomposition characteristics to observe the real material degradation phenomenon is essential. The endothermic pyrolysis mechanism during the ablation process depends on the temperature, heat flux, time duration of the fire, and type of aerodynamic stress (e.g., tension, compression, bending, and torsion) [68]. In the initial stage of the heat flux, heat transfer takes place through pure conduction and hence it causes rise in temperature. At a particular temperature, the pyrolysis reaction (thermal degradation) takes place followed by the elimination of pendant aromatic rings and retention of all aromatic carbons
[69]. This reaction causes the formation of a thermally crosslinked intermediate structure of new liquid or gas phases. In the decomposition process, resin evaporation takes place and causes development of pressure in the composite due to the penetration of evaporated gases through the fiber laminates. The excess pressure creates volume expansion in the remaining matrix and intense material degradation rate causes carbon laminates to lose their structural integrity. During thermal degradation thermal conductivity $(K)$, specific heat $(C)$, and density $(\rho)$ of the composite change [70]. Fiber decomposition behaviour depends on the fiber reinforcement density area. The fiber degrades to cone shape fiber during ablation in high fiber density area. In the low fiber density area, the fibers get weakened during ablation and peel off from the matrix due to aerodynamic stresses [71].

6.2. Pyrolysis Mechanism of Carbon Based Polymer Matrix. Pyrolysis of carbon based polymer matrix takes place through a three stage process. First stage of the pyrolysis mechanism demonstrates the formation of additional cross-links as a result of two condensation reactions between functional groups of the cured phenolic. At second stage, breakage of the cross-links occurred followed by the evolution of methane, hydrogen and carbon monoxide. Similarly, final stage causes stripping of the hydrogen atoms from the ring structure and evolution of hydrogen gas. In pyrolysis reactions, the phenolic matrix converts into amorphous carbon with less structural integrity. This is due to the complete elimination of the noncarbon species and char of coalesced carbon rings formation during pyrolysis. Evolution of gas during the pyrolysis mechanism is controlled by controlling the heating rate of the composite [72]. Clarity in the physiochemical reaction in pyrolysis mechanism leads to optimization of the factor of safety during the design of the composite heat shields. Optimized factor of safety leads to an efficient design 


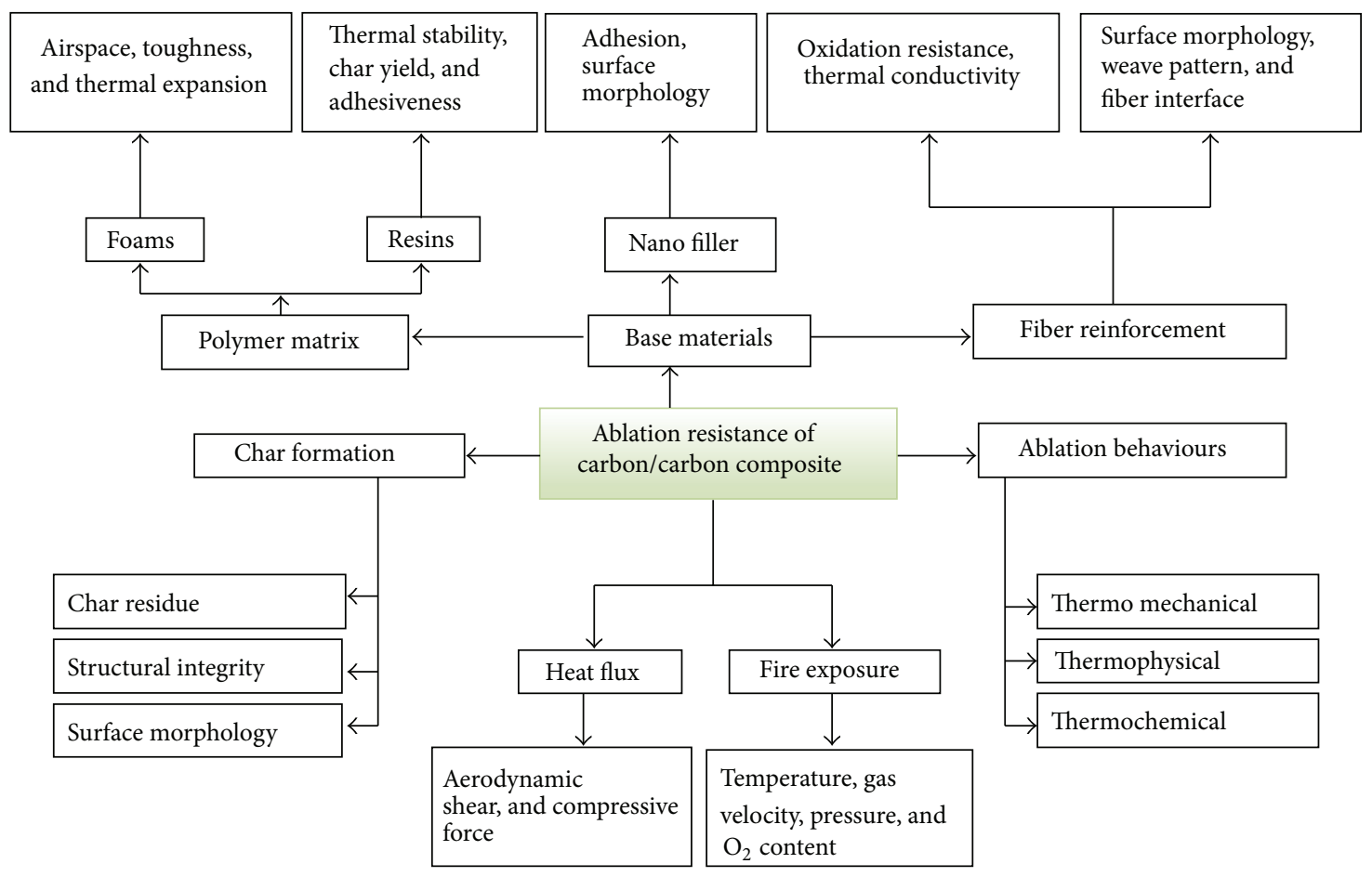

FIGURE 9: Parameters affecting ablation resistance of phenolic matrix ablatives.

of heat shields with least material wastages and max thermal protection.

6.3. Char Formation. Phenolic carbon composites are the charring ablators which degrade into a carbonaceous residue (char) during ablation. The char formation leads to an effective thermal barrier layer against the material degradation. During ablation, the presence of highly ionized air in the heating region causes complex pyrolysis reactions at the surface and within the boundary layer [73]. Microstructural study of the char layer reveals that gas-filled pores in the polymer matrix and the fibre-matrix interface are more prone to decomposition during pyrolysis mechanism [74]. The decomposition gases cause pores to grow and coalesce in the hot viscous matrix under the high internal pressures. This mechanism leads to the weakening of the strength of the char layer. Florio et al. calculated the rise in local pressure due to the coalesces of the pores and noticed that local pressure rises as high as 15 times the ambient pressure for a phenolic matrix laminate. This high pressure is strong enough to cause delamination, matrix cracking, and fibre-matrix deboning [75]. The key factors which decide the reinforcing effect of fillers on the char layer is their high melting point and surface adhesion. Effect of graphene on the char layer has been studied by many research groups. Graphene nanofillers act as cementing agents and form network structure in the char layer and improve the char layer resistance against stripping during high flow rate of hot gases [74]. Char-fiber reaction is an intensive area in the thermal decomposition of composite panel where char structural integrity is highly dependent. Torre et al. studied the effect of nanosilica in the thermal insulation properties of the char layer. The higher concentration of the nanosilica effectively freezes the high viscosity and forms a melt layer over the ablated surface of the composite [75]. This causes an improvement in the protection of the charred substrate and reduces the erosion rate of composite surface during the jet of hot gases. Natali et al. have showed that the presence of silica on the surface ensured higher reradiation efficiency since the adhesion of the charred layer over the virgin materials was strong enough for a longer period of time. Presence of nanosilica leads to a carbothermal reduction between silica and carbon, thereby making them an effective heat insulator and ablative resistant during the thermal degradation [76].

\section{Thermal Analysis of the Composite Materials}

Thermal analysis and failure modelling of the composite materials play a significant role in the design of composites for heat shielding application. Main focus in the thermal analysis is based on temperature distribution through the composite laminates during fire exposure [77]. Fiber reinforced composite structures create explosion at high temperature $\left(>2000^{\circ} \mathrm{C}\right)$ due to their organic content in the elemental composition. The fire reaction behaviour of structural composite materials and their characterization account for information such as their time-to-ignition, heat release rate, limiting oxygen index, flame spread, and smoke density [78]. The thermal, chemical, and mechanical behaviour of the composite panels during the fire exposure are effectively analyzed through structural response of composite and degradation kinetics. 
Less research has been performed on laminates with reactive fibres, sandwich composite materials and the dynamics of the fire and the fire interaction with composite surface is totally ignored, that is, assumptions during analysis based on constant heat flux or temperature conditions. Xie and DesJardin developed a coupled fluid-structure modelling approach for analysing the heat transfer from combustion flame into the ablative materials [79]. Decomposition of matrix during ablation makes changes in boundary conditions and heat release rate. These phenomena influence the ablation behaviour of the composites and can be effectively analysed through a coupled approach between the fire and composite using computational fluid mechanics (CFD) and finite element analysis (FEA) [80]. CFD is an analytical technique used to quantify the flow dynamics and temperatures of the flame over the composite surface [81]. Thermal modelling developed by Henderson et al. is the common model for calculating the temperature distribution in composites. This one-dimensional nonlinear equation accounts for the energy transfer through heat conduction, pyrolysis mechanism, and diffusion of decomposition gases which is shown in the following [82]:

$$
\begin{aligned}
\rho C_{p} \frac{\partial T}{\partial t}= & k_{\perp} \frac{\partial^{2} T}{\partial x^{2}}+\frac{\partial k_{\perp}}{\partial x} \frac{\partial T}{\partial x}-\dot{m}_{g} C_{p(g)} \frac{\partial T}{\partial x} \\
& -\frac{\partial \rho}{\partial t}\left(Q_{p}+h_{c}-h_{g}\right),
\end{aligned}
$$

where $h_{c}$ and $h_{g}$ represent the enthalpy of solid and gas phase

$$
\begin{gathered}
h_{c}=\int_{T_{\infty}}^{T} C_{p} d T, \\
h_{g}=\int_{T_{\infty}}^{T} C_{p(g)} d T .
\end{gathered}
$$

The first term one the right hand side of (1) accounts for the heat conduction through thickness of the composite laminate. The second term accounts for the changes in the thermal conductivity with increasing temperature. The third term accounts for the internal convection of thermal energy due to the flow of volatile gases from pyrolysis reaction. Similarly the last term accounts for the temperature change in the composite due to heat generation or consumption resulting from endothermic reaction of the matrix material. Equation (1) presumes a one-dimensional material system with the heat transfer occurring only through thickness direction. Equation (1) is expanded to analyse two- and three-dimensional systems with large amount of empirical data on the thermal and decomposition properties of the composite. Modification of the Henderson's thermal model has been done by many research groups. In the recent period, Gibson et al. slightly modified the Henderson model to include the decomposition reaction rate of the polymer matrix. This model can be used to calculate the mass loss and extent of charring during decomposition [83]. Gibson et al. recently proposed a simplified model by avoiding the use of the Arrhenius decomposition model. The new model "apparent thermal diffusivity (ATD)," involves expression of the thermal diffusivity of the composite as a function of temperature. ATD takes into account the decomposition of the resin, which is endothermic, as well as consequently changes specific heat capacity and thermal conductivity of the composite. The rate dependence of the decomposition behaviour is neglected, with the decomposition state at any temperature being calculated directly from the TGA curve for the polymer matrix.

7.1. Modelling Thermal Properties of Decomposing Composites. Thermal decomposition of the composite material depends on thermal and physical properties such as density, thermal conductivity, specific heat capacity, and gas permeability of both virgin composite and its char residue [82]. Temperature dependence of these properties is important for the prediction of thermal response of the composite during thermal analysis. During thermal decomposition and pyrolysis, density of composite varies significantly. Arrhenius decomposition kinetics is the common approach for finding the change in density with time. The density change in a single stage decomposition reaction is given by the following:

$$
\frac{\partial \rho}{\partial t}=-\left(\rho_{v}-\rho_{c}\right)\left[\frac{\rho-\rho_{c}}{\rho_{v}-\rho_{c}}\right]^{n} A e^{(-E / R T)}
$$

Thermal properties of the fully decomposed phase (char) are difficult to obtain due to unavailability of the measured data. So during thermal analysis the properties of the decomposing composite are assumed to be dependent on the relative mass fractions of the virgin composite and its char. The mass fraction of virgin material in a decomposing composite can be calculated as

$$
F=\left[\frac{\rho-\rho_{c}}{\rho_{v}-\rho_{c}}\right] .
$$

By considering the density changes as a variable element in the matrix decomposition, thermal conductivity of the decomposing composite can be defined as follows:

$$
k(T)=F \cdot k_{v}(T)+(1-F) \cdot k_{c}(T) .
$$

Thermal conductivity depends on the thermal response of composites in fire, considered to be an important parameter for thermal analysis of the composite structure. Henderson and Wiecek have reported that the specific heat capacities for the virgin composite and char depend on the temperature. The specific heat capacity is determined using the following:

$$
C_{p}(T)=F \cdot C_{p(v)}(T)+(1-F) \cdot C_{p(c)}(T) .
$$

By using different parameters, thermal decomposition behaviour of the ablative composite can be well analyzed. However, fire-induced damage such as fibre-matrix debonding, intraply matrix cracking, and fibre damage degrade the thermal properties of the composites. Delaminations of the laminates affect the reduction in thermal conductivity of the virgin composite due to the formation of air gap between debonded ply layers [77]. So there is a requirement for unified damage model by incorporating the influence of various damages in the composite structures during thermal decomposition. 
7.2. Mathematical Model of Phenolic Impregnated Carbon Composite. Pyrolysis mechanism of the carbon-carbon composite is as same as other ablative materials in terms of thermal decomposition, char morphology, and delamination. In case of phenolic resin, the matrix decomposition takes place at a particular temperature followed by the char layer ablation at a little higher temperature [78]. Thermal response of carbon-carbon composite at various zones (virgin material zone, pyrolysis zone, and porous char layer zone) is different and the thermal analysis needs to consider for this variation in thermal response. follows.

The main assumptions during the ablation models are as

(1) Energy transfer through mass diffusion is neglected.

(2) Mass transfer takes place mainly through the movement of pyrolysis gases.

(3) Pyrolysis gases considered "ideal gases" and their properties are constant.

(4) The specific heat capacity of the composite is a mass weighted average of the relative mass fractions of polymer, char, and fibre remaining in the composite.

(5) Heat conductivity coefficient mainly depends on the temperature variation.

(6) Thermal decomposition is a single stage process and considered as first-order reaction.

Heating region in the ablative composite is composed of the ionized air that has dissociated. Mass and energy transfer of the volatile products result in complex chemical reactions at the surface and within the boundary layer. The balance between the convective energy, chemical energy, and net radiation at the ablative composite surface are as follows [79]:

$$
\begin{aligned}
\rho_{e} \mu_{e} C_{H}\left(H_{r}-h_{e w}\right)+\rho_{e} \mu_{e} C_{M} \\
\quad \times\left[\sum\left(Z_{i e}^{n}-Z_{i v}^{n}\right) h_{i}^{T v}-B^{\prime} h_{w}\right]+\dot{m}_{c} h_{c}+\dot{m}_{g} h_{g} \\
+\alpha_{w} q_{\mathrm{rad}}-F \sigma \varepsilon_{w} T_{w}^{4}-q_{\mathrm{cond}}=0 .
\end{aligned}
$$

While considering the reaction inside the ablative composite, the effect of surface recession and pyrolysis gas is to be taken into account because, rate of recession of the material thickness affects the conduction and thermal capacitance and escaping of the volatile gas, significantly affecting the thermal decomposition [79]. It can be represented as follows:

$$
\begin{aligned}
\rho c_{p} \frac{\partial T}{\partial t}= & \frac{1}{A} \frac{\partial}{\partial x}\left\{k A \frac{\partial T}{\partial x}\right\}+\left(h_{g}-\bar{h}\right) \frac{\partial p}{\partial t} \\
& +\dot{s} \rho c_{p} \frac{\partial T}{\partial x}+\frac{\dot{m}}{A} \frac{\partial h_{g}}{\partial x} .
\end{aligned}
$$

In thermal shielding composites, there is a constant requirement of mechanistic based models for analyzing the temperature distribution, damage, softening, and failure of the ablative composite. However, surplus empirical data in the mechanistic based model reduce the reliance of the thermal analysis. Extensive studies need to be performed on the ablation mechanism in order to enhance the accuracy and prediction in thermal analysis.

\section{Conclusion}

Ablative materials are efficient thermal insulators due to their uniqueness in accommodating high heat flux and resistance against the heat diffusion. Enhancement in the ablation properties is achievable through matrix modification, improving the surface texture of the fiber reinforcement and dispersion of various nanofillers. Thermal decomposition resistance, ablation resistance, and char retention of the phenolic enhanced with modification of high thermal resistive elements such as Boron, Titanium, and Molybdenum. Elastomeric matrix based heat shielding composites show excellent thermal insulation properties due to their excellent ablation resistance, char yield, and high strain rate. Reinforcing elastomeric matrix system with the synthetic fibers leads to a better ablation properties and enhancement in thermal insulation behaviour. Organic fillers, such as carbon nanotubes, carbon nanofiber, graphite oxide, and graphene, have high potentials in both thermal insulation and char structural integrity. Thermal resistive behaviour of the nanofillers is based on their morphological features and inherent physiochemical characteristics. Inorganic fillers like nanosilica, montmorillonite (MMT) nanoclay, and glass balloons, have higher thermal barrier property. Nanofillers having hollow sphere morphology (Fly ash, Glass balloons) have the effective resistance against heat diffusion rate due to the air space volume in the hollow sphere. Oxidation and aerodynamic erosion resistance of the carbon fiber is achieved by improving the adhesive bonding of the fiber and inorganic coating over the carbon fiber. The main challenge lies in the thermal analysis of the composite materials during ablation. Assessment of the composite properties during the thermal degradation is quite challenging. Combined thermal-structural analysis methodology is needed for carbon-carbon composite materials to deal with the varying working environment and expected service requirement. Furthermore, mechanical damage during the fire exposure, such as delamination cracking and skin-core debonding, needs more attention in the future thermal design of ablation materials.

\section{Abbreviations}

$\{R\}:$ Load vector in transformed eqn

$\partial T: \quad$ Change in temperature

$\partial t: \quad$ Time step

$\partial x$ : Thermal expansion in the through-thickness direction

$\partial \rho$ : Change in density of composite

A: Preexponential factor for decomposition reaction of polymer matrix

$c$ : Specific heat

$C_{p(c)}$ : Specific heat capacity of decomposed (char) composite

$C_{p(v)}$ : Specific heat capacity of virgin composite

E: Activation energy for decomposition reaction of polymer matrix

$F$ : $\quad$ Mass fraction of virgin material in decomposing composite 
$h$ : Convection heat transfer coefficient

$h_{c}$ : Enthalpy of the composite

$h_{g}$ : Enthalpy of the volatile gas

$k_{\perp}$ : Through-thickness thermal conductivity

$k_{c}$ : Thermal conductivity of decomposed (char) composite

$k_{v}$ : Thermal conductivity of virgin composite

$m_{g}$ : Mass flux of volatiles

$n$ : Order of the decomposition reaction of the polymer matrix

$N$ : Diffusion rate of oxygen

$P_{\mathrm{og}}$ : Pressure of oxygen

$q$ : Heat flux per unit area

$Q_{p}$ : Decomposition energy of polymer matrix

$r$ : Molar oxidation rate

$R$ : Universal gas constant

$S$ : Compliance of composite

$T:$ Temperature

$t$ : Time

$T_{\infty}:$ Reference temperature

$T_{\infty}$ : Temperature of medium

$u$ : Flow velocity

$x$ : Distance in through-thickness direction below the fire exposed surface

$\alpha$ : Thermal diffusivity

$\Delta R$ : Surface recession

$\varepsilon: \quad$ Emissivity of the composite

$v$ : Velocity component normal to surface, $\mathrm{m} / \mathrm{s}$

$\rho:$ Instantaneous density of composite

$\rho_{c}$ : Density of decomposed (char) composite

$\rho_{v}$ : Density of virgin composite

$\sigma$ : Stephen-Boltzmann const.

\section{Superscripts/Subscripts}

$c$ : Chemical, composite, and conductivity

$d: \quad$ Diffusion

$s$ : $\quad$ Surface

T: $\quad$ Transpose

$r$ : $\quad$ Radiation, reaction

q: $\quad$ Heat flux

-(dot): Time derivative.

\section{Conflict of Interests}

The authors declare that there is no conflict of interests regarding the publication of this paper.

\section{Acknowledgments}

The authors would like to thank Dr. Prahlada, Vice Chancellor of Defence Institute of Advanced Technology (DIAT), for his support and encouragement. In addition, we are grateful to Group. Captain. T Manoj, Dr. Renuka Gonte, B. N. Sahoo, Premika. G, and Colonel Vijay Kumar DIAT (DU) for proofreading the paper and providing many useful comments.

\section{References}

[1] T.-C. Chen and C.-C. Liu, "Inverse estimation of heat flux and temperature on nozzle throat-insert inner contour," International Journal of Heat and Mass Transfer, vol. 51, no. 13-14, pp. 3571-3581, 2008

[2] Y. Tong, S. Bai, H. Zhang, and Y. Ye, "Laser ablation behavior and mechanism of $\mathrm{C} / \mathrm{SiC}$ composite," Ceramics International, vol. 39, no. 6, pp. 6813-6820, 2013.

[3] A. P. Mouritz, S. Feih, E. Kandare et al., "Review of fire structural modelling of polymer composites," Composites A, vol. 40, no. 12, pp. 1800-1814, 2009.

[4] Y. Chen, P. Chen, C. Hong, B. Zhang, and D. Hu, "Improved ablation resistance of carbon-phenolic composites by introducing zirconium diboride particles," Composites B, vol. 47, pp. 320$325,2013$.

[5] T. K. Kuo and S. Keswani, "A comprehensive theoretical model for carbon-carbon composite nozzle recession," Combustion Science and Technology, vol. 42, no. 3-4, pp. 145-164, 1985.

[6] P. Thakre and V. Yang, "Chemical erosion of carbon-carbon/ graphite nozzles in solid-propellant rocket motors," Journal of Propulsion and Power, vol. 24, no. 4, pp. 822-833, 2008.

[7] T. Windhorst and G. Blount, "Carbon-carbon composites: a summary of recent developments and applications," Materials and Design, vol. 18, no. 1, pp. 11-15, 1997.

[8] M. H. Al-Saleh and U. Sundararaj, "Review of the mechanical properties of carbon nanofiber/polymer composites," Composites A, vol. 42, no. 12, pp. 2126-2142, 2011.

[9] K. A. Trick and T. E. Saliba, "Mechanisms of the pyrolysis of phenolic resin in a carbon/phenolic composite," Carbon, vol. 33, no. 11, pp. 1509-1515, 1995.

[10] C. Hong, J. Han, and X. Zhag, "Novel phenolic impregnated 3$D$ fine-woven pierced carbon fabric composites: microstructure and ablation behavior," Composites B, vol. 43 , no. 5 , pp. 2389 2394, 2012.

[11] S. Chand, "Review carbon fibers for composites," Journal of Materials Science, vol. 35, no. 6, pp. 1303-1313, 2000.

[12] C. Donghwan, "A microstructural study of the improved ablation resistance of carbon/phenolic composites fabricated using $\mathrm{H}_{3} \mathrm{PO}_{4}$-coated carbon fibres," Journal of Materials Science Letters, vol. 15, no. 20, pp. 1786-1788, 1996.

[13] R. D. Patton, C. U. Pittman Jr., L. Wang, J. R. Hill, and A. Day, "Ablation, mechanical and thermal conductivity properties of vapor grown carbon fiber/phenolic matrix composites," Composites A, vol. 33, no. 2, pp. 243-251, 2002.

[14] F. W. J. van Hattum, A study of the mechanical properties of vapour grown carbon fibres and carbon fibre-thermoplastic composites, [Ph.D. dissertation], Universidade do Minho, 1999, http://repositorium.sdum.uminho.pt/bitstream/1822/282/1/ van\%20Hattum-Tese\%20Doutoramento.pdf.

[15] G. G. Tibbetts, M. L. Lake, K. L. Strong, and B. P. Rice, "A review of the fabrication and properties of vapor-grown carbon nanofiber/polymer composites," Composites Science and Technology, vol. 67, no. 7-8, pp. 1709-1718, 2007.

[16] K. Lozano, "Vapor-grown carbon-fiber composites: processing and electrostatic dissipative applications," Journal of Management, vol. 52, no. 11, pp. 34-36, 2000.

[17] S. R. Dhakate, R. B. Mathur, and T. L. Dhami, "Development of vapor grown carbon fibers (VGCF) reinforced carbon/carbon composites," Journal of Materials Science, vol. 41, no. 13, pp. 4123-4131, 2006 
[18] H. Jaeger and T. Behrsing, "The dual nature of vapour-grown carbon fibres," Composites Science and Technology, vol. 51, no. 2, pp. 231-242, 1994.

[19] J. S. Tate, S. Gaikwad, N. Theodoropoulou, E. Trevino, and J. H. Koo, "Carbon/phenolic nanocomposites as advanced thermal protection material in aerospace applications," Journal of Composites, vol. 2013, Article ID 403656, 9 pages, 2013.

[20] S. G. Advani and C. L. Tucker, "Part B: constitutive equations and flow processing-processing short-fiber systems," in Flow and Rheology in Polymer Composites Manufacturing, S. G. Advani, Ed., vol. 10 of Composite Materials, p. 147, Elsevier Science, 1st edition, 1994.

[21] J. Zhao, "Effect of post production processing on dispersion of carbon nanofibers in water," Industrial \& Engineering Chemistry Research, vol. 50, no. 3, pp. 1599-1604, 2011.

[22] B. John, B. Deependran, G. Joseph, R. C. P. Nair, and K. N. Ninan, "Medium-density ablative composites: processing, characterisation and thermal response under moderate atmospheric re-entry heating conditions," Journal of Materials Science, vol. 46, no. 15, pp. 5017-5028, 2011.

[23] M. Natali, M. Rallini, D. Puglia, J. Kenny, and L. Torre, "EPDM based heat shielding materials for solid rocket motors: a comparative study of different fibrous reinforcements," Polymer Degradation and Stability, vol. 98, no. 11, pp. 2131-2139, 2013.

[24] D. M. Allison, A. J. Marchand, and R. M. Morchat, "Fire performance of composite materials in ships and offshore structures," Marine Structures, vol. 4, no. 2, pp. 129-140, 1991.

[25] S. R. Dhakate, R. B. Mathur, and T. L. Dhami, "Development of vapor grown carbon fibers (VGCF) reinforced carbon/carbon composites," Journal of Materials Science, vol. 41, no. 13, pp. 4123-4131, 2006.

[26] R. Lipton, "Design of functionally graded composite structures in the presence of stress constraints," International Journal of Solids and Structures, vol. 39, no. 9, pp. 2575-2586, 2002.

[27] A. P. Mouritz and A. G. Gibson, "Fire properties of polymer composite materials," in Solid Mechanics and Its Applications, G. M. L. Gladwell Eds, Ed., pp. 143-163, Springer, Amsterdam, The Netherlands, 1st edition, 2006.

[28] C. P. R. Nair, "Advances in addition-cure phenolic resins," Progress in Polymer Science, vol. 29, no. 5, pp. 401-498, 2004.

[29] Y. Zhang, S. Shen, and Y. Liu, "The effect of titanium incorporation on the thermal stability of phenol-formaldehyde resin and its carbonization microstructure," Polymer Degradation and Stability, vol. 98, no. 2, pp. 514-518, 2013.

[30] C. Luo, W. Xie, and P. E. DesJardin, "Fluid-structure simulations of composite material response for fire environments," Fire Technology, vol. 47, no. 4, pp. 887-912, 2011.

[31] G. Yi and F. Yan, "Mechanical and tribological properties of phenolic resin-based friction composites filled with several inorganic fillers," Wear, vol. 262, no. 1-2, pp. 121-129, 2007.

[32] L. K. Kucner and H. L. McManus, "Experimental studies of composite laminates damaged by fire," in Proceedings of the 26th International SAMPE Technical Conference, vol. 44, pp. 341-353, Paris, France, October 1994.

[33] J. Wang, H. Jiang, and N. Jiang, "Study on the pyrolysis of phenol-formaldehyde (PF) resin and modified PF resin," Thermochimica Acta, vol. 496, no. 1-2, pp. 136-142, 2009.

[34] H. Fan, X. Li, Y. Liu, and R. Yang, "Thermal curing and degradation mechanism of polyhedral oligomeric octa(propargylaminophenyl)silsesquioxane," Polymer Degradation and Stability, vol. 98, no. 1, pp. 281-287, 2013.
[35] D. Wei, D. Li, L. Zhang, Z. Zhao, and Y. Ao, "Study on phenolic resin foam modified by montmorillonite and carbon fibers," Procedia Engineering, vol. 27, pp. 374-383, 2012.

[36] J. Zhou, Z. Yao, Y. Chen, D. Wei, and Y. Wu, "Thermomechanical analyses of phenolic foam reinforced with glass fiber mat," Materials \& Design, vol. 51, pp. 131-135, 2013.

[37] H. Shen, A. J. Lavoie, and S. R. Nutt, "Enhanced peel resistance of fiber reinforced phenolic foams," Composites A, vol. 34, no. 10, pp. 941-948, 2003.

[38] L. Zhang and J. Ma, "Effect of coupling agent on mechanical properties of hollow carbon microsphere/phenolic resin syntactic foam," Composites Science and Technology, vol. 70, no. 8, pp. 1265-1271, 2010.

[39] S. Lei, Q. Guo, J. Shi, and L. Liu, "Preparation of phenolicbased carbon foam with controllable pore structure and high compressive strength," Carbon, vol. 48, no. 9, pp. 2644-2646, 2010.

[40] J. Zhou, Z. Yao, Y. Chen, D. Wei, and Y. Wu, “Thermomechanical analyses of phenolic foam reinforced with glass fiber mat," Materials \& Design, vol. 51, pp. 131-135, 2013.

[41] Z. Jia, G. Li, Y. Yu, G. Sui, H. Liu, and Y. Li, "Effects of pretreated polysulfonamide pulp on the ablation behavior of EPDM composites," Materials Chemistry and Physics, vol. 112, no. 3, pp. 823-830, 2008.

[42] C. M. Bhuvaneswari, M. S. Sureshkumar, S. D. Kakade, and M. Gupta, "Ethylene-propylene diene rubber as a futuristic elastomer for insulation of solid rocket motors," Defence Science Journal, vol. 56, no. 3, pp. 309-320, 2006.

[43] W. K. Ho, J. H. Koo, and O. A. Ezekoye, "Thermoplastic polyurethane elastomer nanocomposites: morphology, thermophysical, and flammability properties," Journal of Nanomaterials, vol. 2010, Article ID 583234, 11 pages, 2010.

[44] A. S. Deuri and A. K. Bhowmick, "Ageing of rocket insulator compound based on EPDM," Polymer Degradation and Stability, vol. 16, no. 3, pp. 221-239, 1986.

[45] X. Jia, G. Li, Y. Yu et al., "Ablation and thermal properties of ethylene-propylene-diene elastomer composites reinforced with polysulfonamide short fibers," Journal of Applied Polymer Science, vol. 113, no. 1, pp. 283-289, 2009.

[46] A. F. Ahmed and S. V. Hoa, "Thermal insulation by heat resistant polymers for solid rocket motor insulation," Journal of Composite Materials, vol. 46, no. 13, pp. 1549-1559, 2012.

[47] M. Tirumali, K. Balasubramanian, and A. Kumaraswamy, "Epoxy composites of graphene oxide (GO): a review," in Proceedings of the IEEE International Conference on Research and Development Prospects on Engineering and Technology (ICRDPET '13), vol. 1, p. 94, Nagapattinam, India, March 2013.

[48] A. K. Dash, D. N. Thatoi, and M. K. Sarangi, "Analysis of the mechanical characteristics of a red mud filled hybridized composite," in Proceedings of the International Conference on Frontiers in Automobile and Mechanical Engineering (FAME '10), pp. 8-11, November 2010.

[49] M. M. Zurale and S. J. Bhide, "Properties of fillers and reinforcing fibers," Mechanics of Composite Materials, vol. 34, no. 5, pp. 463-472, 1998.

[50] C. Luo and P. E. DesJardin, "Thermo-mechanical damage modeling of a glass-phenolic composite material," Composites Science and Technology, vol. 67, no. 7-8, pp. 1475-1488, 2007.

[51] H. L. McManus, "Prediction of fire damage to composite aircraft structures," in Proceedings of the 9th International Conference on Composite Materials (ICCM-9 '93), vol. 58, pp. 929-936, Madrid, Spain, 1993. 
[52] I. Srikanth, A. Daniel, S. Kumar et al., "Nano silica modified carbon-phenolic composites for enhanced ablation resistance," Scripta Materialia, vol. 63, no. 2, pp. 200-203, 2010.

[53] J. Xiao, J. Chen, H. Zhou, and Q. Zhang, "Study of several organic resin coatings as anti-ablation coatings for supersonic craft control actuator," Materials Science and Engineering A, vol. 452-453, pp. 23-30, 2007.

[54] I. Srikanth, N. Padmavathi, S. Kumar, P. Ghosal, A. Kumar, and C. Subrahmanyam, "Mechanical, thermal and ablative properties of zirconia, CNT modified carbon/phenolic composites," Composites Science and Technology, vol. 80, pp. 1-7, 2013.

[55] K.-Z. Li, X.-T. Shen, H.-J. Li, S.-Y. Zhang, T. Feng, and L.L. Zhang, "Ablation of the carbon/carbon composite nozzlethroats in a small solid rocket motor," Carbon, vol. 49, no. 4, pp. 1208-1215, 2011.

[56] Y. Xu, W. Zhang, D. Chamoret, and M. Domaszewski, "Minimizing thermal residual stresses in $\mathrm{C} / \mathrm{SiC}$ functionally graded material coating of $\mathrm{C} / \mathrm{C}$ composites by using particle swarm optimization algorithm," Computational Materials Science, vol. 61, pp. 99-105, 2012.

[57] V. A. Rozenenkova, N. A. Mironova, S. S. Solntsev, and S. V. Gavrilov, "Ceramic coatings for functionally graded high-temperature heat-shielding materials," Glass and Ceramics, vol. 70, no. 1-2, pp. 26-28, 2013.

[58] C. C. Ma and Y. T. Chen, "Theoretical analysis of heat conduction problems of nonhomogeneous functionally graded materials for a layer sandwiched between two half-planes," Acta Mechanica, vol. 221, no. 3-4, pp. 223-237, 2011.

[59] H. Guo, K. A. Khor, Y. C. Boey, and X. Miao, "Laminated and functionally graded hydroxyapatite/yttria stabilized tetragonal zirconia composites fabricated by spark plasma sintering," Biomaterials, vol. 24, no. 4, pp. 667-675, 2003.

[60] G. Zhang, Q. Guo, K. Wang et al., "Finite element design of $\mathrm{SiC} / \mathrm{C}$ functionally graded materials for ablation resistance application," Materials Science and Engineering A, vol. 488, no. 1-2, pp. 45-49, 2008.

[61] E. Bafekrpour, C. Yang, M. Natali, and B. Fox, "Functionally graded carbon nanofiber/phenolic nanocomposites and their mechanical properties," Composites A, vol. 54, pp. 124-134, 2013.

[62] J. H. Koo, H. Stretz, A. Bray et al., "Nanostructured materials for rocket propulsion system: recent progress," in Proceedings of the 44th AIAA/ASME/ASCE/AHS/ASC Structures, Structural Dynamics, and Materials Conference, p. 1769, Virginia, Va, USA, April 2003.

[63] J. S. Tate, S. Gaikwad, N. Theodoropoulou, E. Trevino, and J. H. Koo, "Carbon/phenolic nanocomposites as advanced thermal protection material in aerospace applications," Journal of Composites, vol. 2013, Article ID 403656, 9 pages, 2013.

[64] P. Thakre and V. Yang, "Chemical erosion of carbon-carbon/ graphite nozzles in solid-propellant rocket motors," Journal of Propulsion and Power, vol. 24, no. 4, pp. 822-833, 2008.

[65] A. J. Goupee and S. S. Vel, “Transient multiscale thermoelastic analysis of functionally graded materials," Composite Structures, vol. 92, no. 6, pp. 1372-1390, 2010.

[66] J. Kim, S. W. Lee, and S. K. Won, "Time-to-failure of compressively loaded composite structures exposed to fire," Journal of Composite Materials, vol. 41, no. 22, pp. 2715-2735, 2007.

[67] C. Luo and P. E. Des Jardin, "Thermo-mechanical damage modeling of a glass-phenolic composite material," Composites Science and Technology, vol. 67, no. 7-8, pp. 1475-1488, 2007.
[68] R. Palaninathan, "Behavior of carbon-carbon composite under intense heating," International Journal of Aerospace Engineering, vol. 2010, Article ID 257957, 7 pages, 2010.

[69] T. Lippert and J. T. Dickinson, "Chemical and spectroscopic aspects of polymer ablation: special features and novel directions," Chemical Reviews, vol. 103, no. 2, pp. 453-486, 2003.

[70] W. Xie and P. E. DesJardin, "An embedded upward flame spread model using 2D direct numerical simulations," Combustion and Flame, vol. 156, no. 2, pp. 522-530, 2009.

[71] G. Pulci, J. Tirillò, F. Marra, F. Fossati, C. Bartuli, and T. Valente, "Carbon-phenolic ablative materials for re-entry space vehicles: manufacturing and properties," Composites A, vol. 41, no. 10, pp. 1483-1490, 2010.

[72] V. Srebrenkoska, G. Bogoeva-Gaceva, and D. Dimeski, "Composite material based on an ablative phenolic resin and carbon fibers," Journal of the Serbian Chemical Society, vol. 74, no. 4, pp. 441-453, 2009.

[73] L. Chen, C. Luo, J. Lua, and J. Shi, "A direct coupling approach for fire and composite structure interaction," in Proceedings of the 17th International Conference on Composite Materials (ICCM-17 '09), Edinburgh International Convention Centre (EICC), Edinburgh, UK, July 2009.

[74] J. Florio Jr., J. B. Henderson, F. L. Test, and R. Hariharan, "A study of the effects of the assumption of local-thermal equilibrium on the overall thermally-induced response of a decomposing, glass-filled polymer composite," International Journal of Heat and Mass Transfer, vol. 34, no. 1, pp. 135-147, 1991.

[75] L. Torre, J. M. Kenny, and A. M. Maffezzoli, "Degradation behaviour of a composite material for thermal protection systems part I-experimental characterization," Journal of Materials Science, vol. 33, no. 12, pp. 3137-3143, 1998.

[76] Y. Hu, X. W. Zhang, and H. You, "Morphology measurement on phenolic-resin/vitreous-silica-fabric ablation composites modified with tetraethoxysilicate and silsesquioxanes," Applied Mechanics and Materials, vol. 333-335, pp. 1934-1937, 2013.

[77] A. R. Bahramian, M. Kokabi, M. H. N. Famili, and M. H. Beheshty, "Ablation and thermal degradation behaviour of a composite based on resol type phenolic resin: Process modeling and experimental," Polymer, vol. 47, no. 10, pp. 3661-3673, 2006.

[78] A. N. Negovskii, A. V. Drozdov, V. V. Kutanyak et al., "Experimental equipment for the evaluation of the strength characteristics of carbon-carbon composite mateials within the temperature range $20-2200^{\circ}$ C, 'Strength of Materials, vol. 31, no. 3, pp. 319-325, 1999.

[79] W. Xie and P. E. DesJardin, "A level set embedded interface method for conjugate heat transfer simulations of low speed 2D flows," Computers and Fluids, vol. 37, no. 10, pp. 1262-1275, 2008.

[80] J. G. Quintiere, R. N. Walters, and S. Crowley, "Flammability properties of aircraft carbon-fiber structural composite," Technical Report DOT/FAA/AR-07/57, 2007, http://www.fire.tc .faa.gov/pdf/07-57.pdf.

[81] G. L. Vignoles, Y. Aspa, and M. Quintard, "Modelling of carboncarbon composite ablation in rocket nozzles," Composites Science and Technology, vol. 70, no. 9, pp. 1303-1311, 2010.

[82] J. B. Henderson, J. A. Wiebelt, and M. R. Tant, "Model for the thermal response of polymer composite materials with experimental verification," Journal of Composite Materials, vol. 19, no. 6, pp. 579-595, 1985.

[83] A. G. Gibson, Y.-S. Wu, H. W. Chandler, J. A. D. Wilcox, and P. Bettess, "Model for the thermal performance of thick composite laminates in hydrocarbon fires," Revue de l'Institute Francais du Petrole, vol. 50, no. 1, pp. 69-74, 1995. 

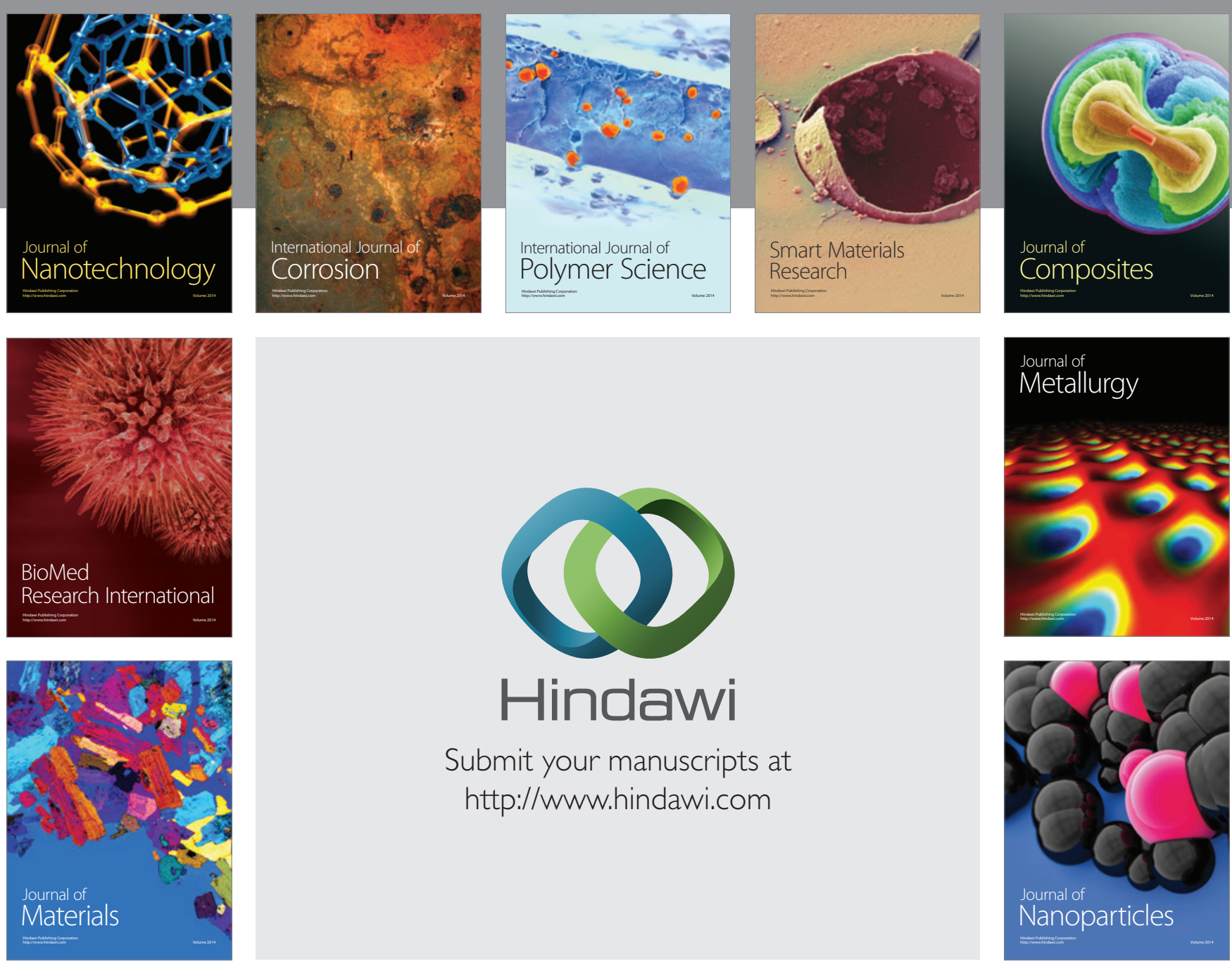

Submit your manuscripts at http://www.hindawi.com
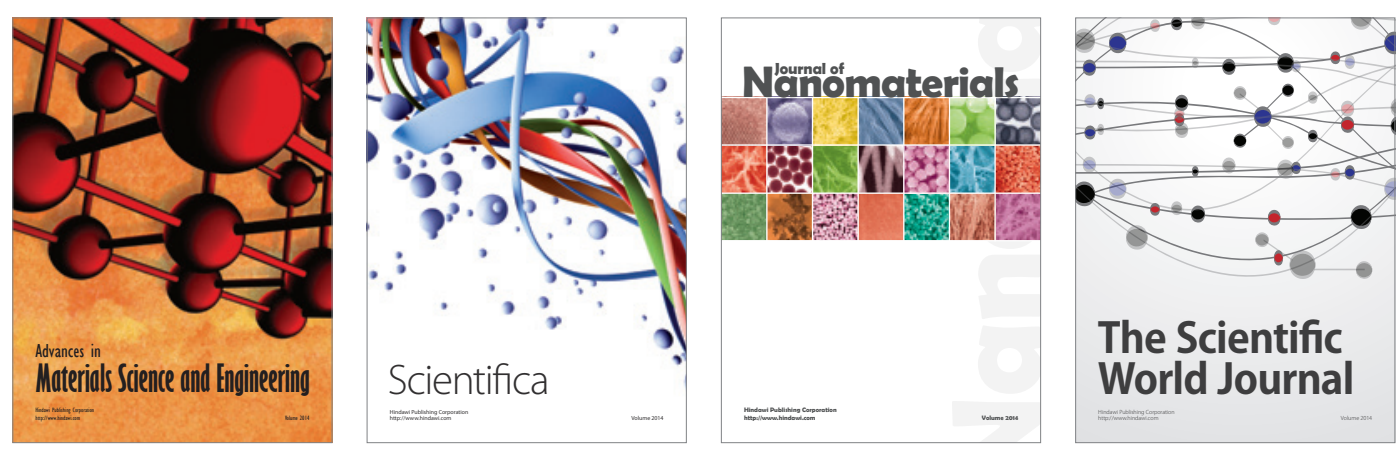

\section{The Scientific World Journal}
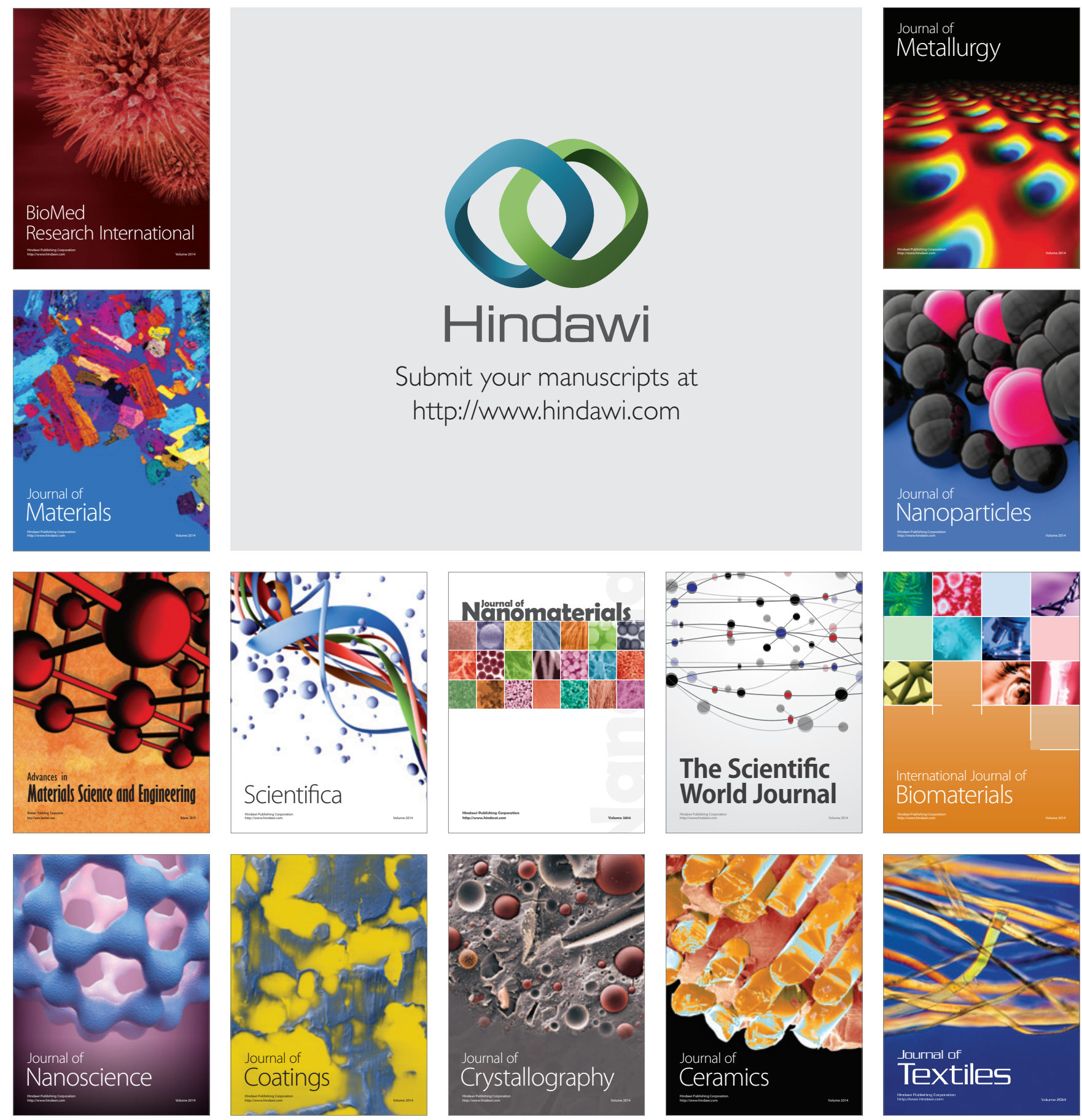